\title{
Postural Analysis of Four Jobs on Two Building Construction Sites: an Experience of Using the OWAS Method in Taiwan
}

\author{
Kai Way LI ${ }^{1}$ and Cheng-Lung LEE ${ }^{2}$ \\ ${ }^{1}$ Department of Industrial Management, Chung Hua University and \\ ${ }^{2}$ Institute for Occupational Safety \& Health, Council for Labor Affairs
}

\begin{abstract}
Postural Analysis of Four Jobs on Two Building Construction Sites: an Experience of Using the OWAS Method in Taiwan: Kal Way Ll, et al. Department of Industrial Management, ChungHua University-Ovako Working Postures Analysing System (OWAS) is a widely used method for studying awkward working postures in workplaces. This study with OWAS, analyzed 2,880 working postures for form, scaffold, iron, and cement works at two building construction sites in northern Taiwan. A computer program, CCOWAS, was designed for the study. It was found that more than $30 \%$ of the working postures observed were classified as either AC2 (slightly harmful), AC3 (distinctly harmful), or AC4 (extremely harmful). The percentage of harmful postures for scaffold workers was even as high as $43.3 \%$. Postures that needed to be corrected either soon $(A C 3)$ or immediately (AC4), and corresponding tasks, were identified. The most stressful tasks observed were sawing, positioning and hammering of the forms for form workers; positioning and wire-tying of iron rods for iron workers; brick-laying for cement workers; and manual handling of steel frames in confined spaces for scaffold workers. Improvement of these tasks was discussed. Some hand-intensive activities, such as wire-tying of iron work, were observed. The unnatural hand postures of these activities could not be recorded by means of OWAS. It was therefore recommended that incorporation of hand postures into basic OWAS or the use of supplementary methods is required to identify ergonomic risk factors for iron work or other hand-intensive activities on local construction sites. (J Occup Health 1999; 41: 183-190)
\end{abstract}

Key words: OWAS, Working posture analysis, Construction workers

Ergonomics is the discipline that studies human

Received Oct 22, 1998; Accepted Mar 29, 1999

Correspondence to: $K$.W. Li, Department of Industrial management, Chung Hua University, Hsin-Chu 300, Taiwan characteristics and incorporates such characteristics in the design of jobs, tools, machines and the environment to improve the safety and well-being of humans. The use of ergonomic principles in studying problems in manufacturing industries is very common. Ergonomic study in the construction industry is, however, not common in Taiwan. Heavy physical demands are required in jobs on construction sites. The physical demands made of construction workers may be attributed to the manual handling of constructing materials and the use of tools and machines. Awkward working postures, repetitive use of body segments, forceful movements, vibration and long periods of standing are also sources of the physical work load. The physical work load has been recognized as the cause of musculoskeletal injuries in construction workers. Various investigations concerning musculoskeletal injuries for construction workers have been conducted in European countries ${ }^{1-3)}$. Damlund et al..$^{4)}$ reported the oneyear prevalence of $65 \%$ semi-skilled construction workers who suffered low back pain. A life time prevalence of $80 \%$ for low back pain was reported by Haublein" for concrete reinforcement workers. Jørgensen et al. ${ }^{3)}$ reported that $87 \%$ of bricklayers have low-back problems over their lifetime.

In a survey ${ }^{6}$ conducted by the Institute for Occupational Safety \& Health (IOSH) of the R.O.C. in 1997, 531 construction workers in northern Taiwan were interviewed concerning their experience with musculoskeletal symptoms and work related problems. Ninety-seven percent of the interviewees had experienced musculoskeletal symptoms of numerous kinds over the previous 12 months. Half of the interviewees had their symptoms treated by medical personnel. Low back pain was the major body symptom reported. Thirty-eight percent of the workers experienced low back pain. Aches in the upper extremities were also very common.

As far as work-related activities are concerned, $63 \%$ of the interviewees reported that they did manual materialhandling tasks occasionally, usually or very often. The 
weight of the materials being handled ranged from $5 \mathrm{~kg}$ to nearly $100 \mathrm{~kg}$. Some of the manual material handling tasks were performed by two or more workers together. Fifty-six percent of the workers reported that they used power hand tools occasionally, usually or very often. The weight of the power tools also creates an extra work load for the workers. Seventy-one percent of the workers claimed that they needed to stand for between 4 and $8 \mathrm{~h}$ daily. Sixty percent reported that they squat more or less during their work. The percentages of workers required to twist and bend their trunks during work were $77 \%$ and $83 \%$, respectively. Over $30 \%$ of the interviewees felt that their working environment was poor, in general.

The analysis of workers' subjective opinions, such as the IOSH study, revealed a prevalence and possible causes for the musculoskeletal symptoms. The ergonomic risk factors and problematic tasks cannot, however, be identified easily without a systematic analysis of the jobs. Schneider \& Susi ${ }^{7}$ discussed ergonomic hazards in constructing a new building based on their on-site observations. Their descriptive study identified activities with potential hazards in each construction stage, but no quantitative analysis was performed. Kivi and Mattila ${ }^{1)}$ and Mattila $e t$ al..$^{2)}$ analyzed the working postures of construction workers by the OWAS (Ovako Working Posture Analysing System) method. Their studies indicated that OWAS was a suitable, reliable and practical method for analysing construction jobs. Good documentation by OWAS provided a powerful and reliable basis for work improvement. The adequacy of OWAS in identifying awkward working postures for construction jobs was, however, not mentioned.

Reinforced concrete (RC) structures are the most common types of buildings constructed in Taiwan. The supporting structure of a RC building is entirely made of concrete with steel reinforcement inside. In constructing such a building, a huge amount of manpower is employed in the form, iron reinforcement, cement and scaffold works. These jobs were selected and analyzed in this study.

Specifically, the objectives of this study were to:

1. analyze working postures for the form, iron reinforcement, cement and scaffold jobs on two building construction sites.

2. develop recommendations for work improvement for the construction jobs observed

3. discuss the adequacy of using OWAS in identifying awkward postures for the construction jobs observed

\section{Method and Procedures}

\section{Construction Sites}

Two construction sites of different construction companies in Hsin-Chu, Taiwan participated in the study. At both sites, a seven-floor RC building was being constructed. The managers of the two sites were
Table 1. Tasks performed by the four types of workers

\begin{tabular}{ll}
\hline worker & \multicolumn{1}{c}{ task } \\
\hline form & $\begin{array}{l}\text { manual handling of plywood form and brace } \\
\text { positioning } \\
\text { hammering } \\
\text { sawing } \\
\text { drilling } \\
\text { snap-tying } \\
\text { bracing } \\
\text { stripping } \\
\text { manual handling of scaffold frames and planks } \\
\text { scaffold } \\
\text { assembling } \\
\text { disassembling } \\
\text { manual handing of steel rods } \\
\text { positioning } \\
\text { wire-tying at the intersections of the rods } \\
\text { manual handling of bricks, mortar, etc } \\
\text { brick-laying } \\
\text { mortar finishing } \\
\text { tile-installations }\end{array}$ \\
\hline
\end{tabular}

consulted in the early stages of this study. The tasks performed by the four types of workers, according to the managers, are listed in Table 1. The weight of commonly handled construction materials and hand tools are summarized in Table 2. The construction jobs, such as form work, iron work and scaffold work were all done by different subcontractors. The construction workers work eight and half hours per day, in general, including a one-and-half hour lunch break. Each day starts between 7:30 and 9:00 a.m. and ends between 4:00 and 5:30 p.m. depends on the season, stage of the construction project and compromise between the subcontractors. The workers might work up to twelve hours per day, however, when the construction project is delayed (normally by rain) or at the request of the buyer. Workers' overtime was normal. During the four month field study, jobs in the four major categories mentioned above were observed. For each job, the activities of four workers on two construction sites were video taped. The activities of a total of 16 construction workers were observed.

\section{OWAS method}

The OWAS method was used in this study because (i) it is easy to use, (ii) it can be used to analyze a wide range of different postures, and (iii) it has been reported ${ }^{\prime}$. ${ }^{2,9)}$ as a suitable tool in analyzing construction jobs. The OWAS method, originating at a Finnish steel company ${ }^{8}$, 9), is based on a sampling of the working postures. The working postures are then coded and analyzed. The basic OWAS records the postures of the back, arms and legs which comprise 84 typical working postures. Head/neck 
Table 2. Weights of construction materials and hand tools commonly used

\begin{tabular}{lcc}
\hline material or tool & weight $(\mathrm{kg})$ & size $(\mathrm{m})$ \\
\hline plywood form & $13( \pm 3)$ & $1.8 \times 0.45 \times 0.15$ \\
& $16( \pm 3)$ & $1.8 \times 0.60 \times 0.15$ \\
wood brace & $3-6$ & $3-5$ (length) \\
electric circular saw & 2 & \\
electric drill & 6 & $1.8 \times 0.8 \times 0.03 \emptyset$ \\
U-shaped scaffold frame & 11 & $1.8 \times 30$ \\
plank & 15 & 1.9 (length) \\
metal brace & $<1$ & \\
steel rod & $3-40$ & depending on diameter and length \\
hammer & $0.3-0.7$ & \\
pliers $\cdot$ hook $\cdot$ screw driver & $<0.2$ & \\
mortar-board \& knife & $<0.3$ & \\
brick & 2 & \\
\hline
\end{tabular}

The process of coding and analyzing postures is very time consuming without the use of a computer if the sampling size is large. In order to make the analysis easier, one computer program, CCOWAS (Computerized Chinese OWAS) was designed. CCOWAS, written with macro statements and Visual Basic language, can be used under Window ${ }^{\circledR}$ and $O S 2^{\circledR}$ environment. CCOWAS must be used under a spreadsheet software, such as Microsoft Excel ${ }^{\circledast}$. The input for the program includes two parts: the fundamental information and working postures codes. The fundamental information includes the number of observations, name of the company (and/or construction site), job being studied, name (or identification) of worker and researcher. The working posture codes are comprised of up to a five digit codes for each posture (see Fig. 1). The output of the program includes the frequency of the working postures (see Fig. 2). The AC classification of the working postures and corresponding OWAS code are identified. Frequency of the AC levels for each task is also calculated. CCOWAS can be installed in a notebook computer which can be used on site for data entry and analysis. This was, however, not performed in the current study because the researchers found it was difficult to code the postures, on site when the workers were moving.

\section{Data Collection}

The age and working experience of the workers involved in the study were $34.6( \pm 9.0)$ and $9.3( \pm 6.4)$ years, respectively. All of the workers were male. The workers participating in this research were assigned arbitrarily by the managers. For each worker, a $1.5 \mathrm{~h}$ videotape was recorded. The videotapes were recorded in the morning (9:30 to 11:00 a.m.) or in the afternoon (2:00 to 3:30 p.m.) depending upon the availability of both the jobs being performed and the researchers. The safety of the researchers on site was also a major issue in determining the time and job to be videotaped. The two recording periods were believed to be representative since the workers performed the tasks identified by the site managers (see Table 1) almost all the time. The videotape was discarded if the worker was idled due to any unexpected event during the recording period. The weight of the load handled was determined after the completion of the videotaping so that the workers' tasks were not disturbed. The videotapes were played back later in the laboratory with a freeze frame every $30 \mathrm{sec}$ so that the working postures (head, back, arms, legs, and weight 
handled) could be coded. For each job, 720 postures $(4 \times 90$ $\times 2$ ) were analyzed.

Two independent observers coded the postures from videotapes at the same time to determine the reliability of the OWAS method. The interobserver reliability was $75 \%$ to $90 \%$ for head/neck postures, $87 \%$ to $98 \%$ for back postures, $97 \%$ to $100 \%$ for arm postures, $93 \%$ to $98 \%$ for leg postures, and $92 \%$ to $100 \%$ for weight handled, respectively. The code for head postures was not used in determining Action Categories since it had not been properly validated ${ }^{(1)}$. The interobserver reliability for head postures was also lower than for the other body parts.

\section{Results}

A total of 2,880 working postures were recorded and analyzed. For the OWAS method, AC2 through AC4 grouped the harmful postures that would require remedial actions. Fig. 3 shows the percentages of observed postures that fell into any of the harmful categories for the four jobs. More than $30 \%$ of the harmful postures were observed for all four jobs. The percentage of harmful postures for scaffold workers was as high as $43.3 \%$. The majority of harmful postures for each job were classified as AC2 level. Table 3 shows the OWAS code for those postures. The most common harmful postures for all the jobs were identified by OAWS code 2121 and 2161 . The ergonomic risk caused by 2121 was the bending of the back. The risk of 2161 was caused by the bending of the back and kneeling on one or both knees simultaneously.

The AC3 and AC4 postures require either soon or immediate remedial actions. These postures for the four jobs are shown in Fig. 4. The numbers of AC 3 postures, for form, iron, cement and scaffold jobs were 24, 29, 30 and 72 , respectively. The numbers of AC4 postures for the four jobs were $5,5,10$ and 7 , respectively.

\section{Discussion}

For form work, the most strenuous postures were postures 4161 and 4241 . The 4161 posture was observed when the workers were sawing, positioning and hammering plywood forms. Two different sizes $(180 \times$ 45 and $180 \times 60 \mathrm{~cm}$ ) of plywood forms were used. The

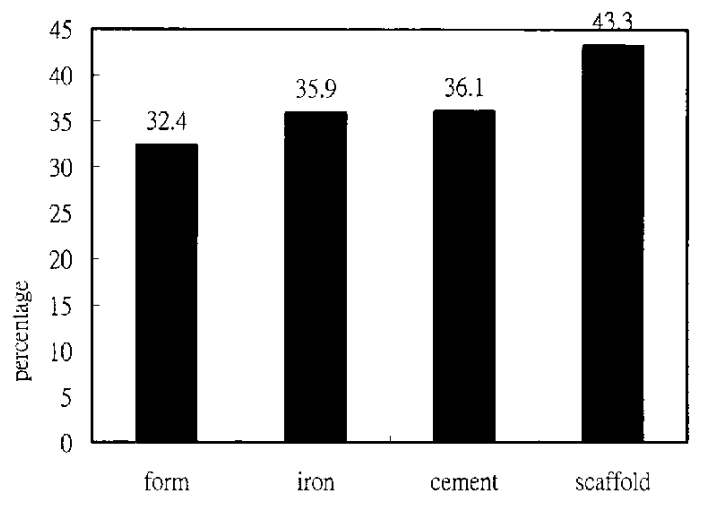

Fig. 3. Percentages of harmful postures for the four jobs

workers had to saw the forms into smaller pieces if they could not find a proper one to use. On both of the sites visited, no saw horse was used. The workers either squatted or knelt when they need to saw a form on the floor. Body twisting occurred when they were handling a form or the electric circular saw from the side. These postures can be reduced if a saw horse (at the elbow height of the workers) is constructed. The 4241 posture was recorded when a worker was positioning the form for a wall. The worker had to adjust his body to the awkward working height. This can be improved by using an 
Table 3. OWAS code of AC2 postures for each job

\begin{tabular}{|c|c|c|c|c|c|c|c|}
\hline \multicolumn{2}{|c|}{ form } & \multicolumn{2}{|c|}{ iron } & \multicolumn{2}{|c|}{ cement } & \multicolumn{2}{|c|}{ scaffold } \\
\hline OWAS code & \# obs & OWAS code & \# obs. & OWAS code & \# obs. & OWAS code & \# obs. \\
\hline 1141 & 5 & 1141 & 8 & 2111 & 1 & 1141 & 1 \\
\hline 1151 & 1 & 1151 & 2 & 2121 & 61 & 1241 & 1 \\
\hline 1341 & 10 & 1251 & 1 & 2122 & 2 & 1242 & 1 \\
\hline 1351 & 2 & 1341 & 1 & 2161 & 135 & 1341 & 1 \\
\hline 2111 & 4 & 2111 & 4 & 2171 & 18 & 2121 & 130 \\
\hline 2121 & 80 & 2121 & 52 & 2221 & 3 & 2122 & 22 \\
\hline 2122 & 4 & 2161 & 152 & & & 2131 & 1 \\
\hline 2161 & 89 & 2171 & 1 & & & 1161 & 41 \\
\hline 2171 & 2 & 2221 & 1 & & & 2163 & 1 \\
\hline 2221 & 3 & 2321 & 2 & & & 2171 & 10 \\
\hline 4111 & 1 & & & & & 2221 & 7 \\
\hline 4121 & 2 & & & & & 2222 & 2 \\
\hline 4221 & 1 & & & & & 2321 & 4 \\
\hline & & & & & & 4121 & 1 \\
\hline & & & & & & 4122 & 1 \\
\hline & & & & & & 4131 & 1 \\
\hline & & & & & & 4221 & 1 \\
\hline total & 204 & & 224 & & 220 & & 226 \\
\hline
\end{tabular}

\begin{tabular}{|c|c|c|c|c|c|}
\hline form & iron & cement & scaffold & scaffold & scaftold \\
\hline $\int 14 !(16)$ & $2141(21)$ & S141 (22) & 22 & $2173(7)$ & $\eta_{3352,11}$ \\
\hline & & & $2123(20)$ & $2261(1)$ & ${ }_{4142}$ \\
\hline $2151(5)$ & & $2151(4)$ & & $3142(1)$ & $\int_{4242(1)}$ \\
\hline $4161(4)$ & $2261(1)$ & $4141(4)$ & & $2342(11)$ & $\sum_{4341(1)}$ \\
\hline$\prod_{4241 \mathrm{al}}$ & $\begin{array}{l}72 \\
3141(1)\end{array}$ & $\begin{array}{l}3 \nu \\
4.161(6))^{b_{1}}\end{array}$ & $2143(8)$ & $3242(1)$ & \\
\hline & 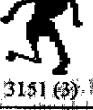 & & $2151(2)$ & & \\
\hline & $\begin{array}{l}M_{2} \\
3351(2)\end{array}$ & & 2172 (1) & דק & \\
\hline
\end{tabular}

adjustable platform. Body twisting can be avoided if the worker simply moves his legs.

There were 16 postures with the OWAS codes of 2141 and five with 2151 observed. These postures were recorded when the workers were positioning, hammering, and drilling. The bending and kneeling/squatting of the workers always occurred when they worked near floor level. A change of posture is not easy if working height cannot be brought to a level near the waist or the elbow. One 2141 posture was observed when a worker was drilling holes in a form. The worker complained that the task was more stressful than the positioning and hammering of the form even though these tasks had the same OWAS code. The drilling task involved holding the electric drill (about $6 \mathrm{~kg}$ ) with the left arm, pulling the trigger, and pushing the drill with the right hand (see Fig. 5). The physical workload was heavy even though the drill weighed less than $10 \mathrm{~kg}$. The author recommended the use of an adjustable support so that the weight of the drill was not supported by the worker.

Posture 2142 involved the manual handling of forms. The load of the weight handled could be reduced with mechanical aids, such as a lifting table, a cart, and so on. Forms also became heavier (up to $3 \mathrm{~kg}$ each) because of

Fig. 4. AC3 \& AC4 working postures for the four jobs. The numbers under the pictures are the OWAS code and number of observation. AC4 postures are marked by dark background. 
saturation with moisture and concrete. Periodic cleaning and exposure to the sun might minimize the extra weight due to concrete and moisture.

For iron workers, the tasks performed included lifting and carrying iron rods from stock piles to the place where needed, positioning of the iron rods, and tying the rods with wire at the intersections. The lifting, carrying and positioning of iron rods were normally performed by two workers because the rods are long and hard to handle. Wire tying was performed individually. For iron workers, the majority of their time was spent in wire tying. More than one hundred intersections may require wire tying on a single beam, column or slab. Sections of wire were carried by the workers. When tying, wire was wrapped around the intersections of the rods and twisted. Wiretying for each intersection took less than $30 \mathrm{sec}$. It could be classified as highly repetitive task, according to PutzAnderson ${ }^{15}$. On one construction site, workers used pliers to twist the wire. Wire-tying hooks, which required much less wrist motion, were used on the other construction sites. The repetitive motion of the wrist, normally observed in industrial production-line activity, could not be recorded by OWAS due to its work sampling nature. And unnatural wrist postures, such as ulnar deviation and flexion, which have been identified as particularly harmful ${ }^{15)}$, could not be recorded either, since there no classification for wrist postures in basic OWAS.

When wire-tying and positioning, the workers must bend, squat or kneel down to reach under knuckle height, such as in a beam or a slab. AC3 code 2141,2142, and AC4 code 3151 were observed when the workers were positioning the iron rods. Postures 2141, 2142, 2151, $2261,3141,3151$ and 3351 were observed when the workers were tying wire. All of these postures were observed when the workers were working at or near floor level (see Fig. 6). An investigation ${ }^{16)}$ of Swedish workers showed that iron reinforcement workers bent over up to $58 \%$ of their work time while working on floor slabs. In

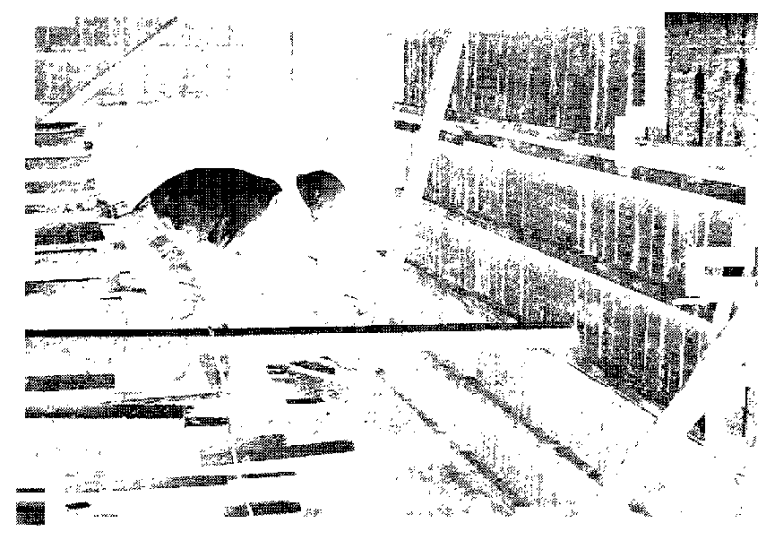

Fig. 5. Drilling task of a form worker order to counterbalance the body, the back muscles must contract statically. Severe muscle fatigue may be developed under such conditions. In addition, excessive load on the spine imposed by the back muscles force causes degenerative changes in the discs of the spine. The degeneration of discs, in turn, may cause chronic back pain ${ }^{17}$. The need of urgent review of these postures has been reported by other authors ${ }^{4)}$. The postures of bending and kneeling/squatting may not be easily changed if the wire-tying tasks must be done below knuckle height level. It was therefore recommended that a unit (such as a beam or slab) of an iron structure be assembled on an adjustable working platform on the floor. The unit may be lifted and moved into position by a crane. This will reduce the need for bending and kneeling/squatting by workers.

The most strenuous task observed for cement workers was brick-laying. Brick-laying has been shown ${ }^{3)}$ to cause severe muscle fatigue. The load on the lumbar spine has also been shown ${ }^{18)}$ to be very high, especially when the hands are working near floor level. Therefore, a high prevalence of low-back problems among workers is not surprising. Postures 4161 and 4141 , both classified as $\mathrm{AC} 4$, were observed when the workers were picking up bricks or mortar from the side and putting them onto a low wall. Four AC3 code $2141 \mathrm{~s}$ were recorded when workers were carrying bricks and buckets of mortar. To reduce body twisting, bricks and buckets of mortar can be placed right in front of the workers (instead of by the side). The use of adjustable scaffolds and brick lifting tables, recommended by other authors ${ }^{1,7)}$, so that proper working height can be maintained may reduce awkward postures when working on a wall. They were, however, of little help in reducing awkward postures when the workers worked on a low wall indoors. AC3 postures 2141 and 2151 were recorded when the workers were finishing a wall with mortar. During this study, several cement workers complained of pain and muscle fatigue

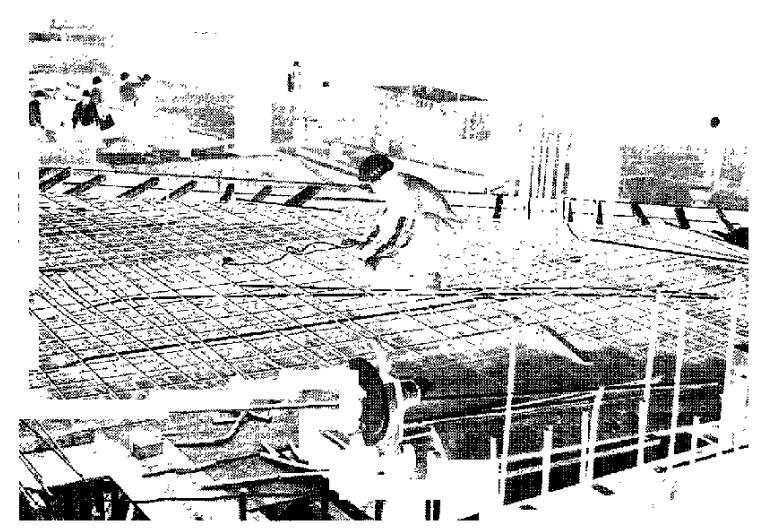

Fig. 6. Wire-tying by iron workers on deck 
in the left shoulder and arm due to the sustained holding of a mortar-board (about $2 \mathrm{~kg}$ with mortar on the board) when doing mortar finishing. The sustained static postures when holding materials were, however, not identified as harmful postures according to OWAS. The OAWS 2141 and 2151 codes identified the harmfulness of bending the body and the leg(s), not the weight handled.

The job of scaffold workers is different from those of other construction workers because they do not stay on the same construction site for a whole day. Scaffold workers go to another site whenever they finish assembling or disassembling scaffolds on one site, and this normally takes less than half day. The tasks of erecting and disassembling scaffolds were ergonomically stressful. Considerable overhead lifting and lowering were required to handle the scaffold frames and planks. The weight of the frames and planks was over $10 \mathrm{~kg}$ each. Sometimes the workers handled two or three pieces of the frame at a time. 1343, 2123 and 2143 (AC3) postures were observed under such conditions. The space on the scaffold was very limited, so that the workers needed to bend the knees, twist and/or bend the trunk when handling the materials. Almost all the AC4 postures, 2342, 3242, 3342, 3252, 3352, 4142, 4242 and 4341 , were observed under such conditions. The use of light scaffold frames and planks was not practical since the scaffolding system has been standardized. The occupational safety and health authorities even encourage construction companies to use heavy planks, according to the site managers, because they believe heavy planks are more stable on a scaffold than light planks. The weight of the frames and planks might be increased (by up to about $2 \mathrm{~kg}$ ) because of concrete adhering to the planks and frames. Periodic cleaning of the scaffold frames and planks will eliminate the extra load. The use of a hoisting device was recommended so that the weight handled by workers is reduced. Screening of personnel might also help. In other words, short individuals may not have to bend their knees and trunks on scaffolds as often as taller persons do because of the limited space. Bending and twisting of the trunk may also be reduced by training personnel to use hoisting devices. Manual handling of metal frame and planks of more than one piece should be prohibited.

\section{Conclusion}

This study employed the OWAS method to study the working postures for four jobs at two construction sites. The aim was to identify the tasks by ergonomic risk factors and develop recommendations for work improvement. A computer program, CCOWAS, was designed and used in this study. This program reduced the amount of data analysis required. A total of 2,880 working postures of 16 workers in two construction sites were videotaped and analyzed. The $\mathrm{AC} 2$ postures, from the output of CCOWAS, were listed. The most problematic working postures found for the four jobs were bending of the back and squatting/kneeling on one or both legs. Frequent handling of heavy materials in stressful postures was found for scaffold workers. The $\mathrm{AC} 3$ and $\mathrm{AC} 4$ postures were identified and work improvements were discussed.

The OWAS method was originally designed to study the working postures in a steel company. This method is suitable and reliable for analysing the tasks at construction sites, according to other authors ${ }^{1.2)}$. It is a proper method for studying working postures involving the movement of whole body. With the help of videotape and computer technology, OWAS can be used efficiently in identifying awkward working postures for the shoulders, back and legs. On the constructions sites we visited, however, a considerable amount of unnatural postures were observed for the wrists of iron workers. These hand tool-induced awkward postures could not be recorded with OWAS. This indicates that basic OWAS was somewhat inadequate in analyzing awkward postures for iron workers. Incorporation of hand postures into OWAS may be required for a complete postural analysis for the handintensive activities on construction sites. Further studies, however, are required for the modification of OWAS. The use of a supplementary method that is suited for distal upper extremity analysis, may also compensate for the shortcomings of OWAS. The observational technique reported by Stetson et al. ${ }^{(9)}$ may be used for this purpose. This technique identifies ergonomic risk factors for the hand and wrist by counting the total number of hand exertions per work cycle and the number of exertions associated with specific risk factors such as high force or adverse postures. Documentation of the hand postures may be established with the specially designed data collection form. A checklist designed for the analysis of hand activities may also be used. Michigan's checklist for upper extremity cumulative trauma disorders ${ }^{20)}$ is a good example. Further study of the hands/wrists of the workers was not done in the current research due to the difficult in viewing postures of the hand and wrist from the videotapes.

Acknowledgment: This research was support financially by a grant (IOSH87-H325) from the National Institute for Occupational Safety \& Health, Council for Labor Affairs, R.O.C.. The development of CCOWAS was support by the National Science Council of R.O.C. under contract No. NSC87-2213-E-216-012 The author would like to thank Perng-Cheng Wei and Ming-Shin Kuo, students of Chung Hua University, for their assistance in the study.

\section{Reference}

1) Kivi P, Mattila M. Analysis and improvement of work postures in the building industry: application of the 
computerized OWAS method. Appl Ergon 1991; 22: 43-48.

2) Mattila M, Karwowski W, Vilkki M. Analysis of working postures in hamming tasks on building construction sites using the computerized OWAS method. Appl Ergon 1993; 24: 405-412.

3) Jørgensen $K$, Jensen $B R$, Kato M. Fatigue development in the lumbar paravertebral muscles of bricklayers during the working day. Int J Ind Ergo 1991; 8: 237-245.

4) Damlund M, Goth S, Hasle P, Munk K. Low back strain in Danish semi-skilled construction workers. Appl Ergon 1986; 17: 31-39.

5) Haublein HG. Berufsbelastung und Bewegungsapparat. VEB Verlag Volk und Gesundheit. Berlin: 1979.

6) Lee CL. The investigation of workers' occupational musculoskeletal problems in building constructions(in Chinese), IOSH86-H328, Institute for Occupational Safety \& Health, R.O.C., 1998:

7) Schneider S, Susi P. Ergonomics and construction: a review of potential hazard in new construction. Am Ind Hyg J 1994; 55: 635-649.

8) Karhu O, Kansi P, Kuorinka I. Correcting working postures in industry: A practical method for analysis. Appl Ergon 1977; 8: 199-201.

9) Karhu O, Harkonen R, Sorvali P, Vepsalainen P. Observing working postures in industry: examples of OWAS application. Appl Ergon 1981; 12: 13-17.

10) Kant I, Notermans JHV, Borm PJA. Observations of working postures in garages using the Ovako Working Posture Analysing System (OWAS) and consequent workload reduction recommendations. Ergonomics 1990; 33: 209-220.

11) Scott GB, Lambe NR. Working pratices in a perchery system, using the OVAKO Working posture Analysing System (OWAS). Appl Ergon 1996; 27: 281-283.

12) Von Stoffert G. Analyse und Einstufung von Korperhaltungen bei der Arbeit nach der OWAS Methode. Z Arbeitswiss 1985; 39: 31-38.

13) Engels JA, Landeweerd JA, Kant Y. An OWAS-based analysis of nurses' working postures. Appl Ergon 1994; 37: 909-919.

14) Sue H. Postural analysis of nursing work. Appl Ergon 1996; 27: 171-176.

15) Putz-Anderson V. Cumulative trauma disorders: a manual for musculoskeletal diseases of the upper limbs. Taylor \& Francis, London, 1988: 54-60.

16) Sarri J, Wickström G. Load in back on concrete reinforcement work, Scand J Work Environ Health 1978; 4. suppl 1: 13-19.

17) Chaffin DB, Andersson GBJ. Occupational Biomechanics, John Wiley \& Sons 1984: 401-402.

18) Jäger M, Luttmann, Laurig W. Lumbar load during onehand bricklaying. Int J Ind Ergon 1991; 8: 261-277.

19) Stetson D, Keyserling WM, Silverstein BA, Leonard J. Observational analysis of the hand and wrist: a pilot study. Appl Occup Environ Hyg 1991; 6: 927-935.

20) Lifshitz Y, Armstrong T. A design checklist for control and prediction of cumulative trauma disorders in hand intensive manual jobs. Proceedings of the $30^{\text {th }}$ Annual Meeting of Human Factor Society 1986: 837-841.

Appendix OWAS code for each body part

\begin{tabular}{lll}
\hline body part & OWAS code & \multicolumn{1}{c}{ description of posture } \\
\hline head & 1 & free \\
& 2 & bent forward \\
& 3 & bent to the side \\
& 4 & bent backward \\
back & 5 & twisted \\
& 1 & straight \\
& 2 & bent \\
arms & 3 & twisted \\
& 4 & twisted and bent \\
& 1 & both arms below shoulder level \\
legs & 2 & one arm at or above should level \\
& 3 & both arms at or above shoulder level \\
& 1 & sitting with legs under seat level \\
& 2 & standing with both legs straight \\
& 3 & standing or kneeling on one leg, leg straight \\
& 4 & standing or kneeling on both legs, legs bent \\
& 5 & standing or kneeling on one leg, leg bent \\
& 6 & kneeling on one or both knees \\
& 7 & walking or moving \\
& 1 & less than 10 kg \\
weight or force handled & 2 & over $10 \mathrm{~kg}$ but less than $20 \mathrm{~kg}$ \\
& 3 & over $20 \mathrm{~kg}$ \\
\hline & &
\end{tabular}

